\title{
Article \\ A Multi-Model-Particle Filtering-Based Prognostic Approach to Consider Uncertainties in RUL Predictions
}

\author{
Amelie Bender
}

check for updates

Citation: Bender, A. A Multi-ModelParticle Filtering-Based Prognostic Approach to Consider Uncertainties in RUL Predictions. Machines 2021, 9 , 210. https://doi.org/10.3390/ machines 9100210

Academic Editor: Antonio J.

Marques Cardoso

Received: 31 August 2021

Accepted: 18 September 2021

Published: 24 September 2021

Publisher's Note: MDPI stays neutral with regard to jurisdictional claims in published maps and institutional affiliations.

Copyright: (C) 2021 by the author. Licensee MDPI, Basel, Switzerland. This article is an open access article distributed under the terms and conditions of the Creative Commons Attribution (CC BY) license (https:// creativecommons.org/licenses/by/ $4.0 /)$.
Dynamics and Mechatronics, Faculty of Mechanical Engineering, Paderborn University, 33098 Paderborn, Germany; amelie.bender@uni-paderborn.de

\begin{abstract}
While increasing digitalization enables multiple advantages for a reliable operation of technical systems, a remaining challenge in the context of condition monitoring is seen in suitable consideration of uncertainties affecting the monitored system. Therefore, a suitable prognostic approach to predict the remaining useful lifetime of complex technical systems is required. To handle different kinds of uncertainties, a novel Multi-Model-Particle Filtering-based prognostic approach is developed and evaluated by the use case of rubber-metal-elements. These elements are maintained preventively due to the strong influence of uncertainties on their behavior. In this paper, two measurement quantities are compared concerning their ability to establish a prediction of the remaining useful lifetime of the monitored elements and the influence of present uncertainties. Based on three performance indices, the results are evaluated. A comparison with predictions of a classical Particle Filter underlines the superiority of the developed Multi-Model-Particle Filter. Finally, the value of the developed method for enabling condition monitoring of technical systems related to uncertainties is given exemplary by a comparison between the preventive and the predictive maintenance strategy for the use case.
\end{abstract}

Keywords: prognostics; RUL predictions; particle filter; uncertainty consideration; Multi-ModelParticle Filter; model-based approach; rubber-metal-elements; predictive maintenance

\section{Introduction}

The major aim of condition monitoring systems (CMS) is to enable condition-based or predictive maintenance. Both maintenance strategies are characterized by reduced risks and costs compared with reactive or preventive maintenance strategies [1]. While conditionbased maintenance is reliant on the current health state of the system in focus, future states to plan the next maintenance action are considered in case of predictive maintenance.

To realize a CMS, various structured procedures are published differing with regard to their level of detail or their aim of monitoring systems [1-5]. This work is based on the procedure of Goebel et al. [2], since it strives for a maintenance decision on the basis of a prediction and it has a comprehensive structure. The procedure strives for predicting the remaining useful life of the monitored system to support maintenance planning. The procedure's six steps are: monitoring of the system, data pre-processing, feature extraction, model development, diagnostics or prognostics and decision making. These steps are coupled with different tasks: Before monitoring, suitable measurement quantities need to be identified. Different requirements, especially the ability of the measurement quantity to describe the degradation of the monitored system, influence the selection process. Popular measurement quantities are vibration- or acoustic-based [6,7]. During recent years, further measurement quantities such as temperature, electrical current, or the level of purity of used oils have been integrated within condition monitoring solutions [1,7-10]. Based on suitable sensors, the technical system in focus can be monitored. Acquired condition monitoring data is analyzed and preprocessed within the second step. From the preprocessed data, various features are extracted in either time-, frequency-, and/or time-frequency-domain. Those features that show the highest degree of information are selected [11]. To enable 
predictive maintenance, a suitable physics-based, empirical, or learned model to predict the remaining useful life of the system needs to be found.

\subsection{Prognostic Approaches}

Prognostic approaches in the field of condition monitoring are divided into three groups: data-driven, model-based, and hybrid methods [12,13]. While data-driven methods extract knowledge about the system from available data, model-based methods rely on physics-based or empirical models of the system's behavior or its degradation developed by humans [2]. Therefore, model-based methods require less data but more system knowledge than data-driven methods. To this end, model-based methods are often more intuitive and more easily assimilated to changing boundary conditions, such as operating conditions [2]. Hybrid methods combine data-driven and model-based approaches to achieve an advantageous prediction. However, hybrid methods often suffer from the disadvantages of the single approaches, e.g., if only a few data are available, the probability of inaccurate prediction is not negligible $[2,3,12,14-16]$.

The most popular model-based prognostic approaches are Kalman and Particle Filtering-based approaches as well as extensions of both [11,17]. Both filters are originally used for state estimation tasks in tracking problems. Due to suitable adaptions for prognostic tasks, Particle Filters are considered as the state-of-the-art model-based prognostic approaches $[17,18]$.

Contrary to a Kalman Filter, a Particle Filter is not constrained to Gaussian distributions. Moreover, it is suitable for non-linear models and enables a straightforward and appropriate consideration of uncertainties in the estimation process $[17,19,20]$. Their structure is introduced in Section 2.

Particle Filters are used multiple times to estimate the remaining useful life of different systems such as bearings [21,22], batteries [23,24], methane compressors [25], or fuel cells [26]. Moreover, physics-based models [13,21,27], as well as empirical models [23,28,29], are implemented for state monitoring of these systems.

For complex systems, approaches that take multiple models into account are preferred for condition monitoring tasks, since they are able to combine different aspects and advantages of the single models [30]. Often, these multi-model approaches aim at a fault detection and isolation [31-33]. A review of Multi-Model-Particle or Kalman Filters is given by Akca and Efe [34]. To improve modeling the complexity of technical systems, a classical Particle Filter can be enhanced to a Multi-Model-Particle Filter that estimates the next state on the basis of more than one model. Hence; Multi-Model-Particle Filtering approaches for prognostics are focused on in this paper. Further literature on this topic is presented in Section 2.3.

\subsection{Uncertainties in Predictions}

Whereas the risks of diagnosing the current health state are based on a misclassification at the current time, the risk in prognostics is based on a deviation between the actual and the predicted state that possibly increases with each further predicted state ahead. The quality of the predicted remaining useful lifetime (RUL) depends on the management of that risk [3]. On the one hand, diagnosis and prognosis complement each other, and sometimes they are combined for a prediction [35]. On the other hand, predictions consider future degradation processes and thereby allow for a more accurate planning of the next maintenance action. However, this is only accountable once the named risk is reduced [11]. Therefore, an important task in that field is the reduction of uncertainty. For an efficient CMS, an accurate prediction is aspired that depends on suitable measurement data, a robust method as well as on a suitable failure threshold [36,37].

Finally, all three faults mentioned above are related to uncertainty. In the literature, sources of uncertainty are sometimes divided into aleatory and epistemic $[38,39]$. Aleatory sources are based on variations that can be explained by physical knowledge. In contrast, knowledge is missing in the case of epistemic uncertainty. However, a general consensus is 
lacking whether a division in aleatory and epistemic sources is expedient for prognostic tasks [37,39]. In Figure 1, various relevant uncertainties for prognostic tasks and their causes are visualized independent of the former division: the uncertainty of the current state, the uncertainty of the future, the modeling uncertainty, and the uncertainty of the prognostic approach $[2,3,12,40-42]$. To handle these uncertainties, they have to be described and modeled, e.g., by qualitative or quantitative methods. Moreover, uncertainties have to be evaluated, e.g., analytically, numerically, or experimentally. Finally, the evaluated uncertainties are reduced, e.g., by assimilation, or prevented, e.g., by different sensors that generate less noise $[3,38]$.

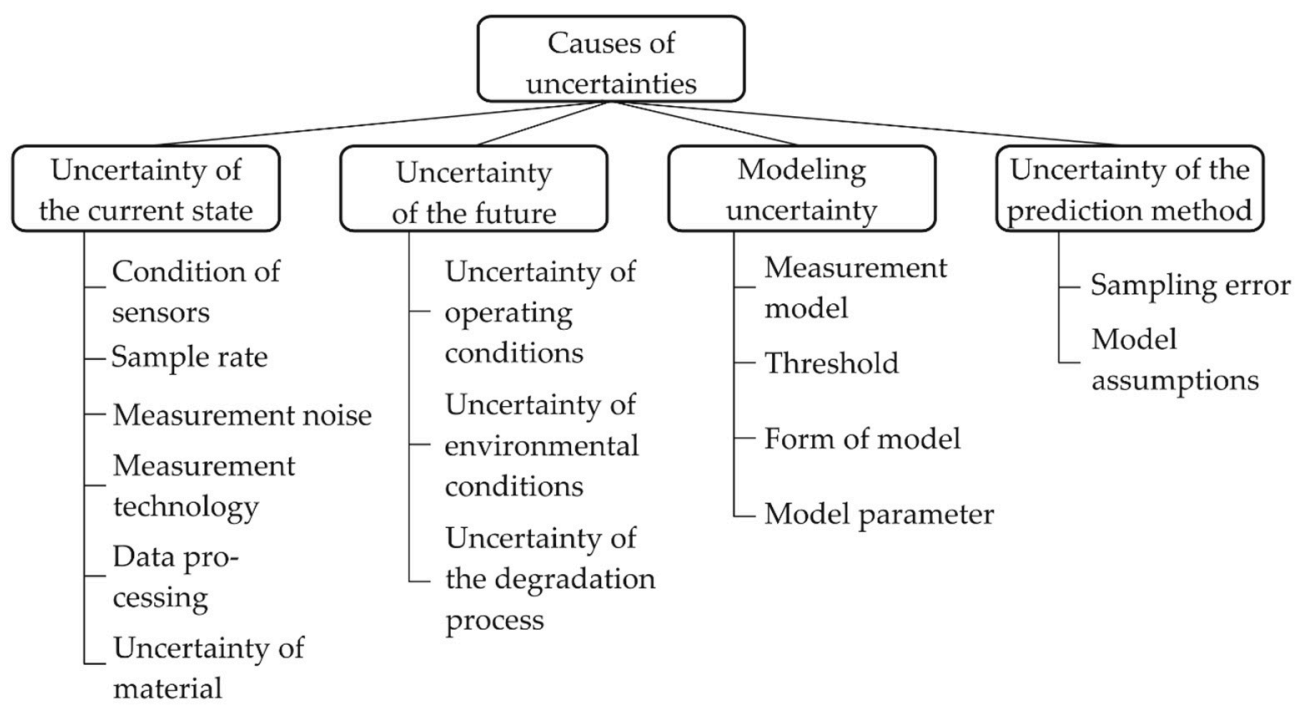

Figure 1. Uncertainties and their causes (based on [2,3,12,40-42].

In the literature, a range of approaches is implemented to consider uncertainties within lifetime predictions [43-46]. Often, individual researches highlight single uncertainty sources. The uncertainty of the current state is focused through sensor monitoring $[47,48]$ or the measurement noise [49]. The modeling uncertainty is typically addressed by a variation of the model parameters $[32,50,51]$. Considering the uncertainty of the future is still a challenge due to the complexity of the task and the significant influence future conditions have on the operating system [37]. However, solutions for particular applications are published, e.g., for wind turbines [40] or aircraft engines [52]. Promising approaches to integrate the uncertainty of the degradation process or the correlated uncertainty of the failure threshold are given in $[36,44,45]$. Moreover, the uncertainty of the prognostic approach is considered, especially data-driven approaches that often lead to point estimates of the predicted RULs being extended [46], or different models are included in one prognostic approach $[53,54]$. However, due to their ability to handle probability distributions and thereby considering uncertainties, sampling-based Bayesian methods such as Particle Filter are often described as favorable $[3,43,55]$.

In most of these papers, only a single uncertainty is brought into focus, such as model uncertainty [55] or uncertainty of the failure threshold [36,44,56]. In this paper, all three topics that influence an accurate prediction including the present uncertainty are tackled.

While condition monitoring solutions can be implemented for different technical systems, systems correlated to a high level of uncertainty are still maintained preventively. As a suitable use case, rubber-metal-elements (RM-elements) are chosen as they are sensitive to various inner and outer factors that lead to uncertainties during operation. In different applications such as wind turbines, trucks, or trains, RM-elements isolate critical system components from unwanted vibrations. To increase availability and safety of these systems, critical system components are monitored by sensors [10,53]. However, critical system components are influenced by the degradation of isolating RM-elements during opera- 
tion. Therefore, a CMS for RM-elements is developed to enable predictive maintenance of these elements.

The paper is structured as follows. In Section 2, a prognostic approach that considers different uncertainties is developed. To this end, a model-based Particle Filtering-based prognostic approach is evolved into a Multi-Model-Particle Filtering-based prognostic approach. In Section 3, in the use case in focus, RM-elements are introduced. Alternative approaches to approximate the service life of these technical systems are presented. Two measurement concepts for predicting the remaining useful lifetime of these elements are developed based on lifetime tests. In Section 4, predictions of the remaining useful lifetime are presented by the developed Multi-Model-Particle Filter based on the two measurement quantities. The two condition monitoring solutions are evaluated using three performance indices. Therefore, the results are compared with predictions based on a classical onemodel Particle Filtering-based prognostic approach. Furthermore, the realized predictions are analyzed in the context of predictive maintenance and a concept is given to enable predictive maintenance for the use case. A conclusion and an outlook is given in Section 4.

\section{Developing a Prognostic Approach Considering Uncertainties}

Since Particle Filters have a high potential to achieve predictions with high accuracy even in the presence of uncertainties [43], a prognostic approach based on the Particle Filtering-based prognostic approach is developed in this work. Furthermore, a modelbased prognostic approach is preferred over a data-driven one as a result of few available data, to enable an accurately predicted remaining useful lifetime. After general stochastic filtering methods are introduced in Section 2.1, Particle Filters are presented in Section 2.2. To consider further uncertainties, a Multi-Model-Particle Filter is developed in Section 2.3. By implementing different models in parallel, the variation within the degradation is considered. Moreover, an approach to estimate adaptive thresholds representing the end of life of technical systems is included in the developed method in Section 2.4. In Section 2.5, the use case of rubber-metal-elements is presented.

\subsection{General Stochastic Filtering Approaches}

To estimate the remaining useful life, Particle and Kalman filters propagate the system state $x_{k}$ at time $t_{k}$ with $k \in \mathbb{N}$ by stochastic estimates of the next state $x_{k+1}$ until a predefined threshold is reached. These estimates rely on the state model $f$ in Equation (1) that considers the previous state $x_{k}$ and some related noise $v_{\mathrm{k}}$.

$$
\mathrm{x}_{\mathrm{k}+1}=\mathrm{f}\left(\mathrm{x}_{\mathrm{k}}, \mathrm{v}_{\mathrm{k}}\right)
$$

The state $x_{k}$ is related to the measurement $z_{k}$ at time $t_{k}$. This relation is modeled by the measurement model $g$ in Equation (2), which considers again some related noise $k_{k}$.

$$
\mathrm{z}_{\mathrm{k}}=\mathrm{g}\left(\mathrm{x}_{\mathrm{k}}, \mathrm{k}_{\mathrm{k}}\right)
$$

In general, the estimation of the state $\mathrm{x}_{\mathrm{k}+1}$ is based on stochastic conditions and can be divided into two steps. In both steps, the Bayes' theorem is used to calculate conditional probabilities for the estimation of $x_{k+1}$. The detailed derivation of the states, the particular probability density functions (PDFs), and the integral formulation can be found in [57,58].

For prognostic tasks, the recursive propagation of the a posterior PDF to estimate $\mathrm{x}_{\mathrm{k}+1}$ can only be solved analytically for a few applications. Numerical solutions are given by extended Kalman or Particle Filtering-based approaches [57].

\subsection{Particle Filter}

Particle Filters are Bayesian state estimators based on Monte Carlo simulation. These filters numerically solve the a posteriori PDF by random samples, called particles. In particular, the propagation of uncertainties is a characteristic of Monte Carlo sampling methods [43]. While Particle Filters for state tracking focus on a time span from the past 
until the current time, Particle Filtering-based prognostic approaches additionally estimate future states $\mathrm{p}$ steps-ahead, for $p \geq 2$ and $p \in \mathbb{N}$ [20]. Thus, for the use in prognosis, the next measurement $z_{k+1}$ is only available if $k$ is dated in the past. Therefore, the second step, the update of the estimated state by a measurement, is only applicable until the current time. For future estimations, the prognostic approach strongly relies on the a priori PDF that is built upon prior knowledge. Finally, the time span of the Particle Filtering-based prognostic approach extends $p$ steps-ahead until a criterion is fulfilled. For RUL estimation, this criterion is given by a failure threshold. In the following, "Particle Filter" is always used in the prognostics' context, unless it is explicitly referred to a different background.

In this work, a sample importance resampling Particle Filtering-based prognostic approach is used to resample particles according to estimated weights for updating the current system's state during the second step $[20,57]$. These weights describe how accurate the particles define the real system's state, which is approximated by the related measurement value and the measurement model. To achieve a suitable diversity of particles combined with reasonable computational costs, resampling is conducted if a defined threshold is reached. That threshold is based on the number of effective particles $[17,28,57]$. For further mathematical background information, see [20,58,59].

Moreover, on the basis of the state estimated by a Particle Filter, the remaining useful life PDF can be derived. For predictive maintenance, a point estimate of the PDF is selected to plan maintenance actions. So, by selecting a suitable point estimate of that density, higher safety regarding late predictions can be achieved. Moreover, many performance indices for prognostic approaches depend on suitable point estimates of the estimated RUL.

\subsection{Multi-Model-Particle Filter}

To consider uncertainties on a larger scale, the classical Particle Filter is extended to a Multi-Model-Particle Filter. While the next state in the classical Particle Filter is estimated by Equation (1), the state estimation in a Multi-Model-Particle Filter relies on a combination of multiple state models

$$
\mathrm{f}_{\text {multi }}\left(\mathrm{x}_{\mathrm{k}}, \mathrm{v}_{\mathrm{k}}\right)=\left\{\begin{array}{c}
\mathrm{f}_{1}\left(\mathrm{x}_{\mathrm{k}}, \mathrm{v}_{\mathrm{k}}\right) \\
\ldots \\
\mathrm{f}_{\mathrm{m}}\left(\mathrm{x}_{\mathrm{k}}, \mathrm{v}_{\mathrm{k}}\right)
\end{array},\right.
$$

for $m \in \mathbb{N}$ state models. Different strategies to combine multiple models in Particle Filters are realized for state tracking and even for prognostic tasks [28,42,60,61]. In [60], Seifzadeh et al. differentiate between three types of Multi-Model-Particle Filters: autonomous, interacting, and variable Multi-Model-Particle Filters. While autonomous filters estimate the result independently, the second type enables an increased performance through the interactivity of the single models or filters. The best flexibility is reached by the variable Multi-Model-Particle Filter, which enables different adaptions, e.g., the definition of transition probabilities [22,42,60,62].

The developed Multi-Model-Particle Filtering-based prognostic approach cannot be attributed to a single type of the Multi-Model-Particle Filter presented by Seifzadeh et al. [60], because it contains multiple aspects. In the developed Multi-Model-Particle Filter, a defined number of state models is integrated and the final result of that multi-model-filter is gained through a parallel combination of the single models, partly similar to ensembles. However, the usage of the single models changes during a prediction. To explain the procedure, it is visualized in Figure 2. Moreover, the pseudo code is given in the Appendix A. 


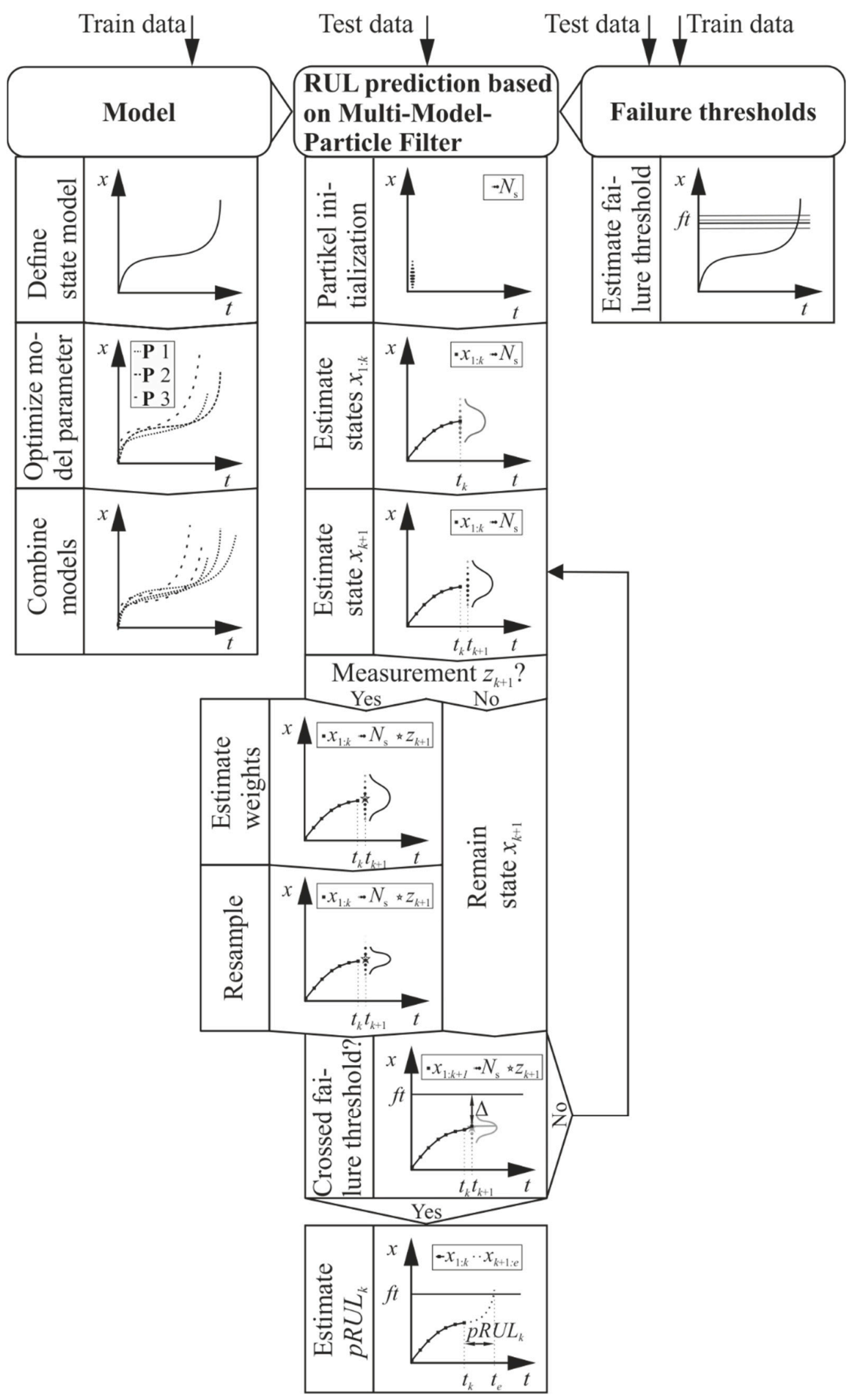

Figure 2. Procedure of RUL prediction based on the developed Multi-Model-Particle Filter [63]. 
The procedure is divided into three parts. On the left side of Figure 2, model definition, choice of model parameters, and model combination are depicted. Contrary to other applications [31,32], the developed models describe the state during the element's whole lifetime. Since the state models can represent different lifetimes, a possibility is implemented to reject automatically state models representing a shorter lifetime when that time has been exceeded by the reached lifetime of the monitored system. The combination of multiple models is done by an expert, thus for different environmental or operational conditions, individual combinations of characteristic state models can be implemented. If only few data are available, for every historical system a model is defined and implemented in this approach. However, the state models do not interact. Based on the single models, particles are initialized and used to describe the states during the RUL prediction process in the middle of Figure 2. In general, each particle i describes one value in the distribution of the next state $x_{k+1}$. Thereby, in the developed Multi-Model-Particle Filter, each particle i is connected to one state model $\mathrm{f}_{\mathrm{m}_{\mathrm{i}}}$ in the state estimation process:

$$
\mathrm{x}_{\mathrm{k}+1}^{\mathrm{i}}=\mathrm{f}_{\mathrm{m}_{\mathrm{i}}}\left(\mathrm{x}_{\mathrm{k}}, \mathrm{v}_{\mathrm{k}}\right) .
$$

Thereby, each state model $\mathrm{f}_{\mathrm{m}_{\mathrm{i}}}$ enables a prediction of the next state, but in the resampling step only the states and the particular models are reused that show a high importance. While at the beginning an equal number of each state models is initialized, due to altering weights depending on the importance of the corresponding particle, the composition of used models alternates based on the resampling step. However, as long as measurement quantities are available, the particles are weighted according to their ability to accurately describe the current state. In this way, the influence of each model and the related particle is changed over the prediction steps. Once no further measurement quantities are available, equal weights of the remaining models are used to estimate the next state. After resampling, a suitable state estimation is derived from the distribution of particles. On the basis of this estimated state, it is checked whether the estimated adaptive threshold $\mathrm{ft}$ is exceeded by the estimated state. Based on that result, either the next state is predicted or the predicted RUL is derived. The estimation of the adaptive thresholds (see right part of Figure 2) is described in the next subsection.

By implementing various models, noise, considering different lifetimes and adaptive thresholds, the uncertainty of the future is represented. Moreover, multiple models enable a higher level of expert knowledge within the approach than the pure implementation of noise in Equations (1) and (2) to represent this uncertainty.

\subsection{Estimating Thresholds Considering Uncertainties}

Even if fixed failure thresholds are state of the art in prognostics, hazard zones [45,64] or adaptive failure thresholds are used in a few research works [36,49]. Within both alternatives, a consideration of uncertainty is enabled [36,65]. While hazard zones describe the uncertainty of the failure by an area or a distribution around a fixed threshold [65], adaptive failure thresholds adapt to the particular system and the present conditions [36]. In this paper, the focus is on adaptive thresholds due to the high uncertainty of the degradations process and the ability of adaptive failure threshold to adapt to varying measurement curves. Depending on the application, the uncertainty of the future influences the degradation behavior and the measurements describing the health state. To consider this uncertainty, two different approaches for defining an adaptive threshold can be found in the literature: The first group of approaches relies solely on knowledge of historical data [44,66], while the second group considers current and historical data [36].

In [67], an approach related to the second group is developed. The main idea remains on the relationship between the stable measurement quantity during the mean time of the system's life and the measurement quantity at the end of the system's lifetime. To estimate these measurement quantities, this approach is based on the slope-related division of the measurement curve in a defined number of phases that describe the health states of the element. The adaptive failure threshold is estimated in consideration of the measurement 
value. If exemplary three health states are present in an arbitrary measurement quantity, it requires a stable quantity $Q_{s}$, given as the mean of the maximum quantity $Q_{s, \max }$ and the minimum quantity $Q_{s, \min }$ during health state $I I$, and the measurement quantity $Q_{e}$ at the end of life, as depicted in Figure 3. The three health states are separated and labelled: health state I (left side), health state II (middle), and health state III (right side). The relation between the measurement quantity $Q_{e}$ and the stable quantity $Q_{s}$ is calculated for all historical data. The mean relation is used to estimate the adaptive threshold of element $\mathrm{j} \mathrm{ft}_{\mathrm{adapt}, \mathrm{j}}$ when the system's state is in health state II. Thus, depending on the current measurement in this health state, an individual threshold is estimated in Equation (5):

$$
\mathrm{ft}_{\text {adapt }, \mathrm{j}}=\frac{1}{\mathrm{~h}} \sum_{\mathrm{i}=1}^{\mathrm{h}}\left(\frac{\mathrm{Q}_{\mathrm{e}, \mathrm{i}}}{\mathrm{Q}_{s, \mathrm{i}}}\right) \cdot \mathrm{Q}_{\mathrm{s}, \mathrm{j}}
$$

with $\mathrm{h}$ as the number of historical datasets and $\mathrm{j}$ as the current element. Moreover, the adaptive threshold is updated during health state II based on new measurements. Thereby, different uncertainties influencing the measurement quantity $Q_{e}$ at the end of life are considered. Furthermore, deviations between the stable quantity of various similar systems are considered as well. The presented approach has been proven to be most suitable for the application in focus, therefore it is implemented in the prognostic approach [67].

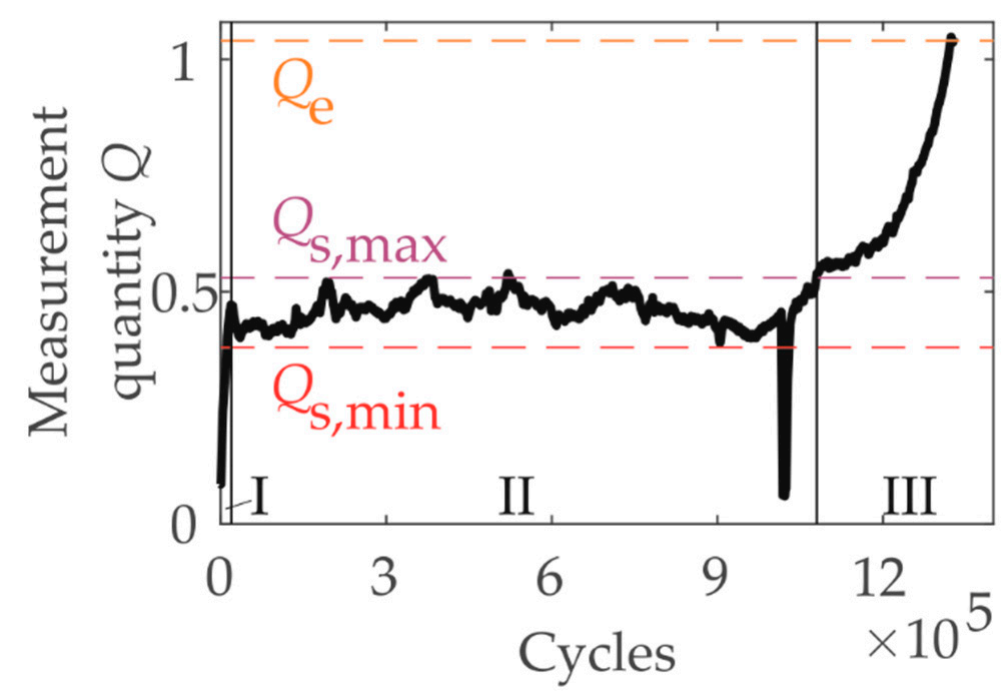

Figure 3. Estimating threshold (based on [63]).

\subsection{Use Case: Rubber-Metal-Elements}

In this subsection, the use case of RM-elements is introduced.

\subsubsection{Attributes and Applications}

To reduce unwanted vibrations in various technical systems, e.g., wind turbines, elements such as RM-elements are integrated. However, these elements show a broad spread of characteristics that lead to different uncertainties in the context of predicting remaining useful lifetime. On the one hand, rubber-elements are characterized by their huge deformability at small loads, their relative high damping capacity as well as their adaptability to a particular application [68]. On the other hand, rubber shows a strong sensitivity to inner and outer factors. A typical inner factor is identified as the material quality influenced through manufacturing processes $[68,69]$. Outer factors influencing the elastomer's behavior are described by time, mechanical and thermal load, as well as environmental influences during the operation $[70,71]$. The elements' sensitivity to these factors results in deviations of characteristic behavior-one reason why these elements are preventively maintained nowadays $[70,71]$. 


\subsubsection{Methods to Approximate Lifetime}

For preventive maintenance planning, the service life of RM-elements is approximated during the design phase using specific concepts as well as expert knowledge of the material and the particular application [72,73]. In the literature, two concepts are used for lifetime approximation: Wöhler's concept and the concept of fracture mechanics. While the former concept approximates the lifetime by Wöhler curves based on fatigue strength tests, the latter concept focuses on cracks and their growth within the material to approximate the lifetime of rubber $[73,74]$. In further research, these two concepts are combined to achieve better accuracy $[71,72,75]$. Giese [76] combines both concepts and takes one step further by measuring the microcracks within the material during his tests. Based on these measurements, the Wöhler curves are approximated. Thereby, the lifetime is updated with every new measurement. However, his method is restricted due to the complex and expensive measurement equipment and boundary conditions of the microcrack measurements. Since cracks are difficult to identify and Wöhler curves rely on a huge data base-especially if the influence of different temperatures is considered-these methods are not suitable for a condition monitoring solution of rubber-elements that is based on few data.

\subsubsection{Lifetime Tests}

To enable a CMS for these elements, run-to-failure data is acquired in lifetime tests on a hydraulic testbed in the laboratory at the chair of Dynamics and Mechatronics, Paderborn University. The testbed is illustrated in Figure 4a. On the left side of Figure 4a, one RMelement is shown tethered in the testbed. The element is composed of an inner steel tube that is connected to a slotted outer steel tube by a vulcanized rubber piece.

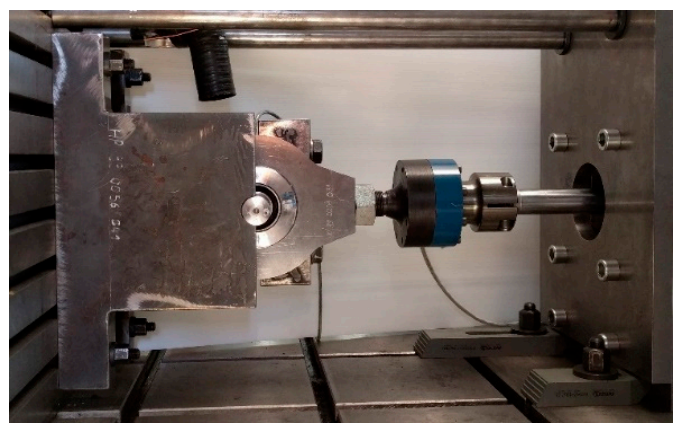

(a)

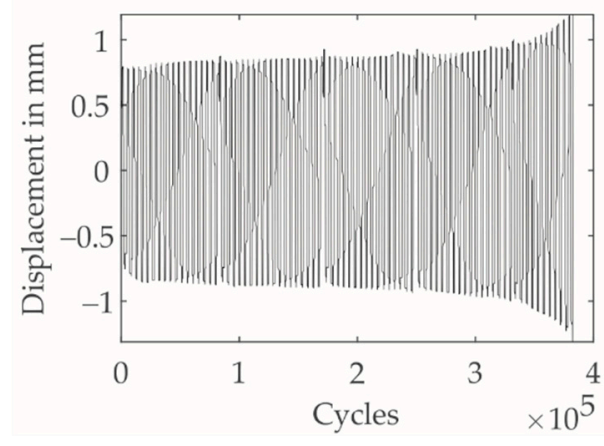

(b)

Figure 4. Lifetime tests of Rubber-Metal-Elements: (a) test bed (based on [77]) and (b) displacement measurement during an element's lifetime.

However, during the lifetime tests, the inner tube is fixed to the massive block on the left side-for illustration purposes the second block is removed to show the RM-element. The outer tube is excited force controlled by a hydraulic cylinder (minimum static force $40 \mathrm{kN}$ for a permitted system pressure of $300 \mathrm{bar}$ ), so that a relative movement within the element is caused. To accelerate the lifetime tests, a higher force amplitude than in real applications is selected. The aim is to achieve a mechanical degradation similar to that in real applications. To reduce thermal influences such as self-heating, an air-cooling system is installed. In lifetime tests, the elements' end of useful life is defined by a maximum displacement amplitude, which is set by domain experts including a safety margin. So, the RM-elements will not break if they exceed the predefined threshold during an application, but their behavior would show unwanted amplitudes.

Figure $4 \mathrm{~b}$ depicts the measured displacement over the lifetime of one element. Especially at the beginning and at the end of the lifetime, changes in the displacement of the element are obvious. During the tests, two groups of experiments are conducted. First, in eight tests (elements 1-8) stationary operating conditions with a force amplitude of $40 \mathrm{kN}$ and a frequency of $2 \mathrm{~Hz}$ of the sinusoidal excitement are realized. To analyze temperature 
influences, in the second group two further tests (elements 11 and 12) are conducted within a heating chamber that enables a constant ambient temperature of $60^{\circ} \mathrm{C}$, while the former tests are conducted under slightly changing ambient temperatures of $17-37^{\circ} \mathrm{C}$. Due to expected influences on lifetime, the force amplitude is reduced to $38 \mathrm{kN}$ during these tests in the heating chamber, while the frequency is kept constant at $2 \mathrm{~Hz}$. These tests were conducted during a joint project with Jörn $\mathrm{GmbH}$, Germany.

\subsubsection{Developing Measurement Concepts}

To select a suitable measurement quantity for condition monitoring, different requirements are defined related to design issues, such as costs, constraints, and assembly issues. In the literature, there is no consensus on the best measurement quantity for monitoring the health state of RM-elements. Furthermore, various features are implemented to describe the end of life. A short overview is given in Table 1. Two often-used characteristics are stiffness and damping work. Both values are not directly measurable, but can be estimated based on hysteresis loops. In Figure 5, hysteresis loops are depicted for three different points of time during a lifetime test. Especially the curve in Figure $5 b$ and the curve in Figure $5 \mathrm{c}$ differ. The displacement amplitude as well as the area within the loop increase due to the element's degradation over time.

Table 1. Used features for failure analysis of rubber elements.

\begin{tabular}{cc}
\hline Feature & Reference \\
\hline Damping work & {$[71,72,78]$} \\
\hline Dynamically stored energy & {$[79]$} \\
\hline Relative change in length & {$[80]$} \\
\hline Crack length & {$[81]$} \\
\hline Crack depth & {$[82]$} \\
\hline Rate of crack growth & {$[83]$} \\
\hline Strain amplitude & {$[84-86]$} \\
\hline Stiffness & {$[73,87-89]$} \\
\hline Tear energy & {$[76,90]$} \\
\hline
\end{tabular}

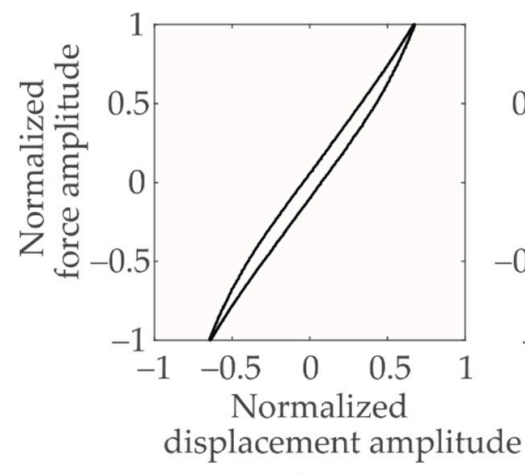

(a)

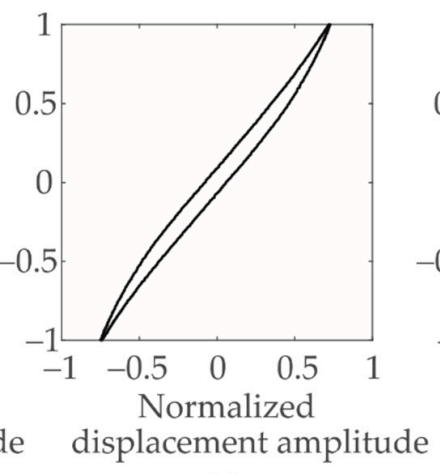

(b)

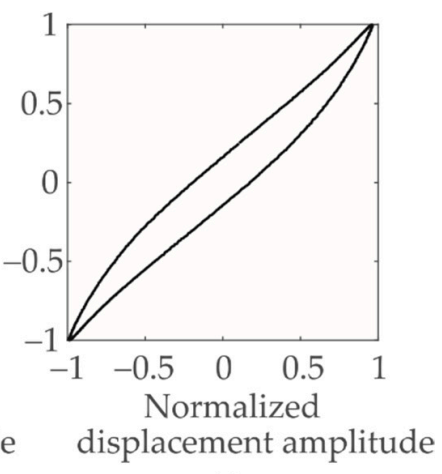

(c)

Figure 5. Hysteresis loops at different points of time: (a) at the beginning, (b) in the middle, and (c) at the end of an element's lifetime [59].

The dissipated energy of the element can be approximated by the area within the loop. Thus, the increase of the dissipated energy can be explained by growing cracks within the rubber and by an increasing temperature due to internal reactions. In this paper, hysteresis loops are not considered. On the one hand, it is hard to measure forces experienced by RM-elements in real applications, on the other hand, two sensors are required, which leads 
to increasing costs. Therefore, a CMS based on one sensor is aspired for. Two concepts are developed to monitor the health state of the focused RM-elements.

\section{Displacement-Based Concept}

The displacement-based concept correlates to the named hysteresis loops if stationary conditions are present. In that case, the force amplitudes are constant and measured displacements can be directly related to the stiffness of the elastomer. Thus, the measurement quantity displacement is often used to describe the health state of RM-elements, especially in force-controlled lifetime tests. During the conducted tests, an integrated magnetostrictive displacement sensor measures the displacement of the hydraulic cylinder. A suitable feature to describe the developing health state of the RM-element is the displacement amplitude illustrated in Figure 6a. The curve shows a characteristic course for rubber-elements that is divided into three health states. At the beginning, the displacement amplitude grows degressively, during health state II the amplitude increases slightly, and during the last health state it increases progressively. So overall, it is possible to find a correlation between the degradation and the displacement amplitude.

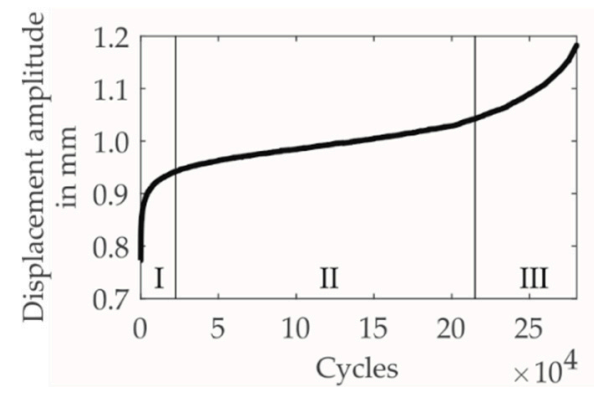

(a)

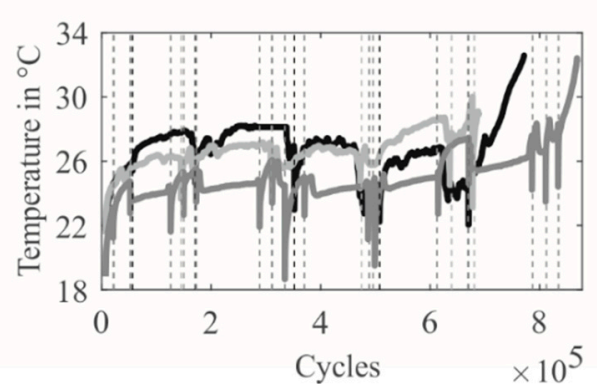

(b)

Figure 6. Measurements during lifetime tests: (a) Displacement amplitude, divided in three phases [63] and (b) element's temperature [91].

A threshold that symbolizes the end of life of the elements under focus is generally defined with regard to a stable amplitude in the main part, the second health state, and depends on the focused application.

\section{Temperature-Based Concept}

The temperature-based concept is linked to the damping work. The damping work describes the energy transformed in heat during a load cycle. Inside elastomer elements, cracks grow as the material degrades and heat develops due to friction of increasing crack surfaces. Therefore, a couple of researchers consider temperature as an influence on the degradation of elastomer elements [72,84,87].

In the first tests, temperature sensors are placed outside the RM-element on the bolt to monitor the temperature. Measurement curves of three elements over the particular lifetime are displayed in Figure 6b. Again, the three health states during the element's lifetime are apparent. However, the element's temperature shows a stronger variation than the displacement amplitudes. The prominent decreases marked by dotted lines correspond to times when the particular test is paused. As these downtimes also occur in real applications, e.g., a parked train, they are considered. Although a correlation between the degradation and the temperature is available, a consistent failure threshold for various elements is lacking. All three elements reach their end of life at different temperatures. While two temperatures are quite similar, the smallest temperature deviates by $4{ }^{\circ} \mathrm{C}$. An adaptive threshold for each element needs to be estimated by the developed slope-based method.

To monitor the temperature in further lifetime tests, one thermocouple is integrated in the outer tube of a RM-element. At that position, they are close to the rubber, but do not cause vulnerable points within it. 


\subsubsection{Preprocessing and Feature Selection}

To develop a CMS, both signal types are preprocessed for data reduction reasons. A similar sample rate and characteristic features are selected, such as the displacement amplitude and the relative temperature. Thereby, the relative temperature is estimated as the difference between the element's temperature and the ambient one.

\subsubsection{Uncertainty Analysis}

As previously described, all four types of uncertainty are tackled in this work. Noise and material uncertainty represent the uncertainty of the current state. Thereby, the selection of a nearly constant material shore hardness of 61 Shore A and a suitable pretension are the main factors to reduce this uncertainty. The uncertainty of the future, especially of the degradation process is considered. In the temperature-based concept, the ambient temperature is additionally integrated within the selected feature. The modeling uncertainty is given by the approach of a Multi-Model-Particle Filter and also in the case of the temperature-based concept by estimating adaptive failure thresholds. Furthermore, the uncertainty of the prognostic approach is reduced through a high number of samples and different model assumptions. Uncertainties, visible in the measurements, are discussed in the following.

In seven lifetime tests, both measurement quantities, are measured. While the temperature curves are exemplarily presented in Figure 6b, in Figure 7 displacement amplitudes of the seven tested elements are given. Each measurement shows the characteristic curve. Nevertheless, differences become apparent in the single levels of the amplitudes, the duration of the three health states, their gradients, and especially the reached lifetime of each element. As illustrated in Figure 6b, the displacement amplitudes in Figure 7 are characterized by less variations during the lifetime tests compared to the temperatures.

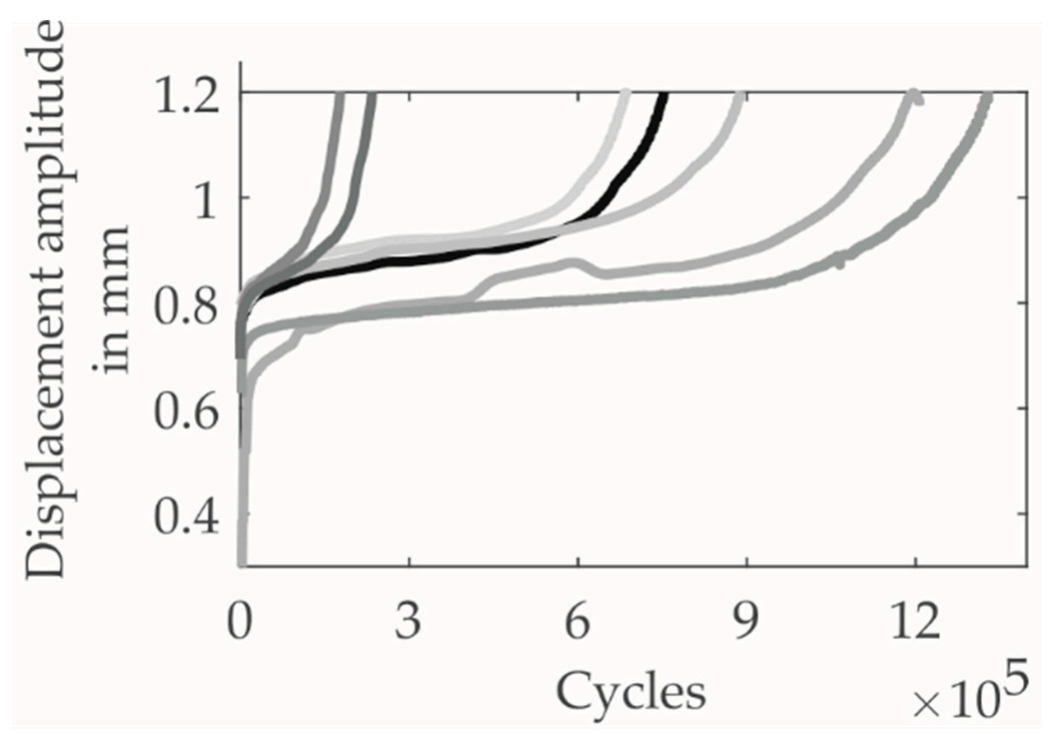

Figure 7. Deviations in displacement amplitudes.

To highlight the uncertainty at the beginning of each lifetime test, the deviations of the two measurement quantities at the beginning of the elements' lifetime are presented in Figure 8 . The uncertainty is characterized by the median value, represented by the vertical line inside each box, and the size of each box, representing the 25th and 75th percentile. For both measurement quantities, the two groups of experiments are compared. Two points are emphasized. Firstly, there is a hint that the influence of the heating chamber is already apparent at the beginning of each experiment, given by different median values for the two groups of experiments. However, the variations of the displacement amplitude of the stationary group, depicted in Figure 8a, implies that similar displacement amplitudes 
occur in the heating chamber as well. However, less variations are observed during measurements in the heating chamber. The difference and therefore the influence of the higher ambient temperature in the heating chamber is, as expected, more pronounced on the relative temperature. Secondly, the variation of the relative temperature is relatively huge for both groups of experiments as can be seen in Figure $8 \mathrm{~b}$. The deviations are comparable, but the mean values differ by $3^{\circ} \mathrm{C}$. This represents a rather huge impact by a mean failure threshold of $9{ }^{\circ} \mathrm{C}$ for the stationary group and a mean failure threshold of $5{ }^{\circ} \mathrm{C}$ for the heat chamber group. It is concluded that the uncertainty related to the relative temperature is already higher at the beginning of an element's lifetime compared with the uncertainty related to the displacement amplitude. Analyzing run-to-failure data of the elements in focus confirms these findings. The uncertainty related to the temperature measurement is higher.

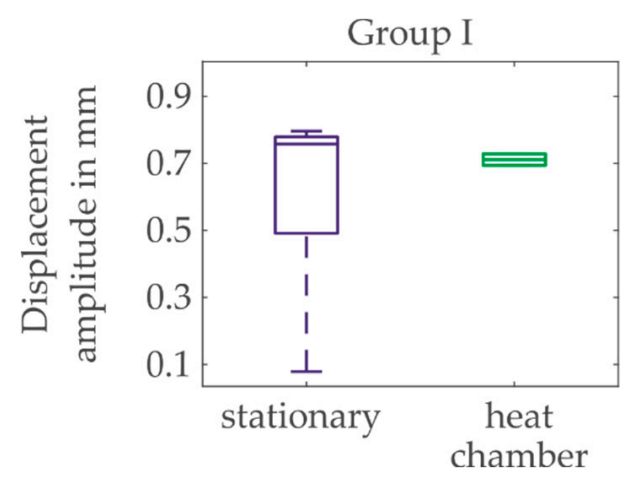

(a)

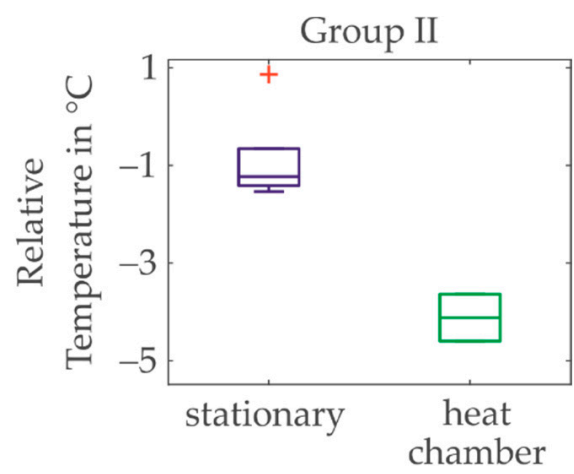

(b)

Figure 8. Uncertainties at the beginning of the element's lifetime for (a) displacement amplitude and (b) relative temperature [63].

Due to the presented differences between the two experimental groups, separation of these groups is integrated within the modeling approach. For each group, the corresponding state models are provided within the prognostic approach. The two experimental groups are described in Section 2.5.3 in the context of lifetime tests and the realized operating conditions. Thus, the developed Multi-Model-Particle Filter is suitable for different operating conditions.

The parameters of the Particle Filter are approximated based on the particular measurement quantity. The named deviations are considered, e.g., the smaller noises in the curves of individual displacement amplitudes. To enable predictions, models are needed to describe the degradation of the RM-elements. Since no physical model is known to describe the developing degradation in terms of displacement or temperature, an empirical model is defined. The empirical state model to estimate the next state is a combination of two exponential functions as given in Equation (6)

$$
\mathrm{x}_{\mathrm{k}+1}=\frac{\mathrm{x}_{\mathrm{k}}}{2} \cdot\left(\mathrm{e}^{p_{2} \cdot\left(\frac{\mathrm{t}_{\mathrm{k}+1}}{p_{3}}\right)^{p_{4}}}+\mathrm{e}^{\frac{p_{1}}{p_{5} \cdot t_{k+1}+1}}\right)+v_{\mathrm{k}+1} \mathrm{x}
$$

with the model parameters $p_{1} \ldots p_{5}$. These parameters are estimated individually for each RM-element through optimization. Hence, such a state model is derived for each measurement quantity of each historical element and embedded in the Multi-ModelParticle Filter. Therefore, the state $\mathrm{x}$ in Equation (6) is replaced by the displacement amplitude or the relative temperature. Thus, the selection of the model noise $v$ depends on the discrepancy between the selected model and the measurement quantity. The comparison of model and measurement is shown exemplarily Figure 9 for the relative temperature. The general course of the developing state can be described by the model. However, the deviations within the curves are not modeled by the state model. 


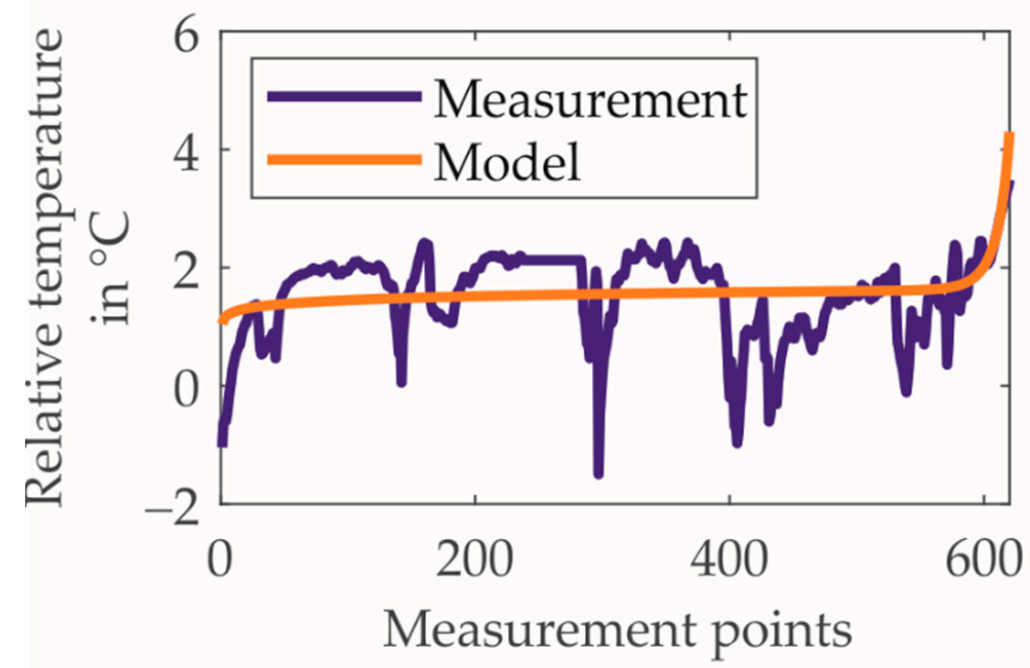

Figure 9. Comparison of model and measurement [63].

The mean squared error between model and data for all seven elements is $0.826{ }^{\circ} \mathrm{C}^{2}$ for temperature measurements and $0.002 \mathrm{~mm}^{2}$ for displacement measurements. The difference between these two errors is again an indication of less deviations within the displacement amplitudes. Thus, the model noise $v$ for predictions based on the displacement amplitude is smaller than the one for predictions based on the relative temperature. Measurement noise is often modeled as a Gaussian distribution [17], even if Particle Filtering-based approaches enable different distributions. The frequency distribution of measured temperatures in Figure 10a suggests that a Gaussian distribution is able to characterize the noise within the measurements. It is assumed that the measured displacements show similar behavior. Figure 10b depicts the histogram of the difference between the optimized model and the particular measured relative temperature for one lifetime test. The best fitted distributions are the normal and generalized extreme value (GEV) distribution. For most of the elements, the results of these two distributions are similar. Again, it is assumed that that difference shows a similar characteristic for displacement measurements. Therefore, in this work model, noise is realized as a normal distributed value around a mean value depending on the particular measurement quantity.

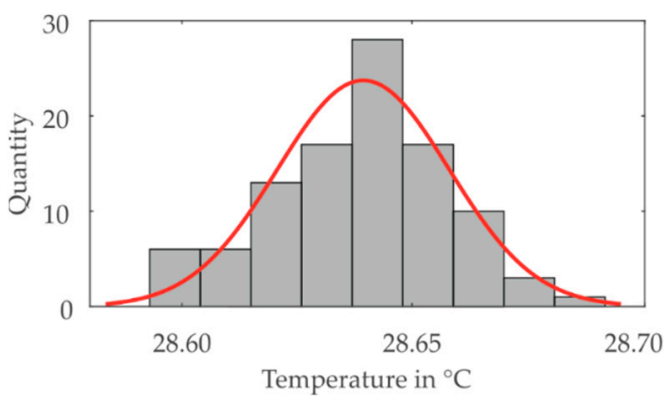

(a)

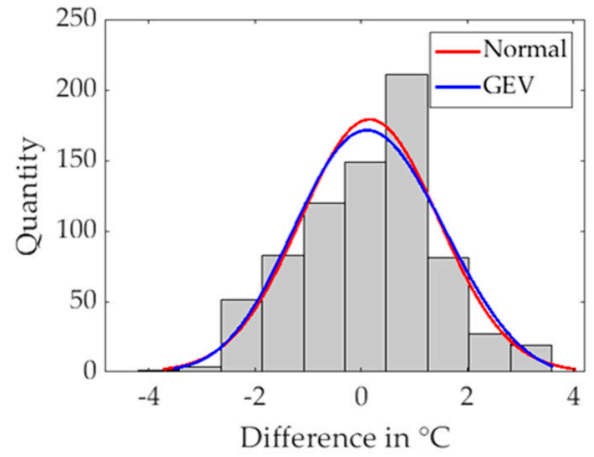

(b)

Figure 10. Analysis of uncertainty: (a) Frequency distribution of measured temperature [63] and (b) approximation of the distribution of the difference between measurement and model by a normal and a generalized extreme value (GEV) distribution. 


\section{Evaluation of the Developed Condition Monitoring System of Rubber-Metal-Elements}

In this section, the developed approach is evaluated by the use case of RM-elements. For both measurement concepts, developed in Section 2.5.4, RUL predictions are evaluated based on run-to-failure data measured during lifetime tests. The predictions are analyzed based on the three performance indices: mean absolute percentage error, rate of negative errors and prognostic horizon. The results are discussed and their meaning in the context of appropriate maintenance strategies is underlined.

\subsection{Predictions of RUL}

For each element in focus, predictions are realized at discrete time points during its lifetime. To achieve a comparison that is independent of the individual lifetime, those time points extend from 15 until $95 \%$ of the reached lifetime for each element. The RUL is estimated in load cycles, a typical unit in industrial applications. For the evaluation, a point estimate of the RUL distribution is chosen. Which one is chosen depends on the application. In [63], a study of different point estimates for temperature measurements of this use case has shown that the mean value of the distribution leads to the best results over all tested elements. To evaluate the predictions, three performance indices are implemented $[3,37,92,93]$.

The mean absolute percentage error (MAPE) as an error-index between the actual RUL (aRUL) and the predicted RUL (pRUL) is defined by

$$
\text { MAPE }=\frac{1}{\mathrm{~N}_{\mathrm{P}}} \sum_{n=1}^{\mathrm{N}_{\mathrm{P}}} \frac{\mathrm{aRUL}_{\mathrm{n}}-\mathrm{pRUL}_{\mathrm{n}}}{\mathrm{aRUL}_{\mathrm{n}}} \cdot 100 \%,
$$

with $\mathrm{N}_{\mathrm{P}}$ as the sum of all prediction time points and $\mathrm{n}$ as the index of the focused time point. The rate of negative errors correlates to the rate of too large predictions that lead to an undesired breakdown of the monitored element. Therefore, the sum of events when Equation (8)

$$
\mathrm{aRUL}_{\mathrm{n}}-\mathrm{pRUL}_{\mathrm{n}}<0
$$

is true is related to $\mathrm{N}_{P}$. While MAPE and the rate of negative errors are time-independent indices, the prognostic horizon $(\mathrm{PH})$ takes time dependency into account. It is defined as the time between the end of life $t_{e}$ and the first prediction time point $n$ from which all following predictions are within a defined threshold $\alpha$. That threshold spreads a tolerance band around the actual RUL. The PH is defined by

$$
\mathrm{PH}=\mathrm{t}_{\mathrm{e}}-\mathrm{t}_{\mathrm{n} \alpha} .
$$

To consider the relatively huge deviations between elements' lifetime, the threshold $\alpha$ depends on the standard deviation of the expected lifetime that is estimated based on historical data. To conclude, all three performance indices evaluate different aspects of the prediction.

In Figure 11, a general impression of the realized predictions of the developed MultiModel-Particle Filter for the elements of the stationary group is given. The predicted RULs (black dots) are depicted and compared with the actual RULs (black line) over the discrete prediction time points for the temperature measurements. The standard deviation of the predicted RULS $\sigma$ (pRUL) (grey area) is estimated based on the particles of the MultiModel-Particle Filter and varies depending on the particular element, e.g., the predictions of element 3 show wide variations and therefore a higher uncertainty. This behavior symbolizes an uncertainty related to the prognostic approach. The PH is marked by a grey arrow. The necessary threshold $\alpha$ spreads a band (dashed line) around the actual RUL. For the experiments of the stationary group, a standard deviation of $3 \times 10^{5}$ cycles is represented by the threshold $\alpha$. For the heat chamber group, a standard deviation of $5 \times 10^{4}$ cycles is approximated due to the small database. These thresholds are generously dimensioned, but they characterize the uncertainty within the data. 
(a)

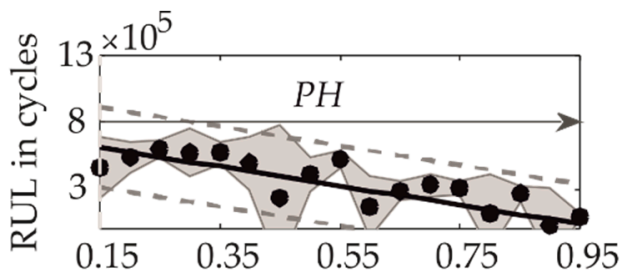

(c)

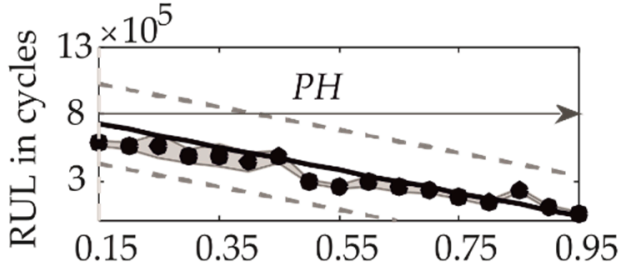

(e)

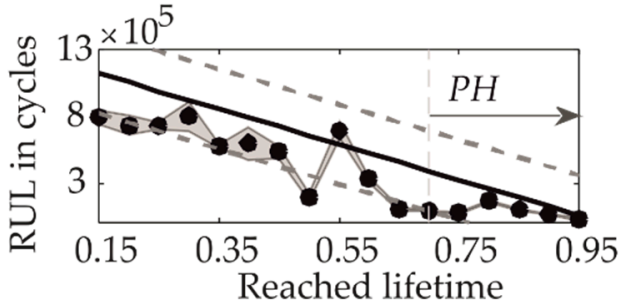

(b)

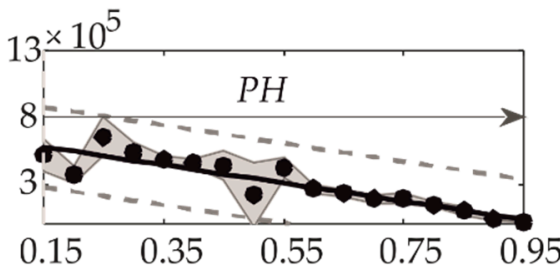

(d)

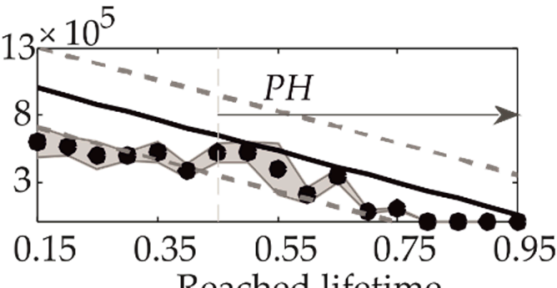

Figure 11. Predictions based on relative temperatures for elements 3-7 in (a-e) [63].

While the PHs can easily be derived visually, MAPE values need to be estimated according to Equation (7). Therefore, the results of all predictions based on displacement and temperature measurements are given in Table 2. Similarities such as similar MAPEs or $\mathrm{PHs}$ can be seen for individual RM-elements like element 4. While large deviations, e.g., between MAPEs are present for RM-elements 3, 7, and 12. For both measurement quantities, the MAPE spreads over a wide range for the monitored elements. However, the maximum MAPEs are reached for the displacement measurements. The rate of negative errors is less than $50 \%$ in the majority for both measurement quantities. However, for displacementbased predictions, higher negative error rates only occur for smaller MAPEs, which is to be preferred over lower MAPEs, but higher rate of negative errors for temperature-based predictions. The range of the PH differs strongly between single elements, sometimes it starts at the first prediction time point, and sometimes it starts after $85 \%$ of reached lifetime. Regarding this performance index, temperature-based predictions perform better as the smallest $\mathrm{PH}$ over all elements starts after $70 \%$ of reached lifetime.

Table 2. Performance indices for the displacement-based and the temperature-based predictions realized by the MultiModel-Particle Filtering-based prognostic approach.

\begin{tabular}{ccccccc}
\hline RM-Element & \multicolumn{2}{c}{ Displacement-Based Concept } & \multicolumn{3}{c}{ Temperature-Based Concept } \\
\hline & Mean MAPE & $\begin{array}{c}\text { Mean Rate of } \\
\text { Negative Errors }\end{array}$ & Mean PH & Mean MAPE & $\begin{array}{c}\text { Mean Rate of } \\
\text { Negative Errors }\end{array}$ & Mean PH \\
\hline 3 & 45.3 & $11 / 17$ & $0.15-0.95$ & 14.9 & $5 / 17$ & $0.15-0.95$ \\
\hline 4 & 19.9 & $8 / 17$ & $0.15-0.95$ & 20.8 & $7 / 17$ & $0.15-0.95$ \\
\hline 5 & 22.7 & $4 / 17$ & $0.15-0.95$ & 41.4 & $0 / 17$ & $0.45-0.95$ \\
\hline 6 & 56.3 & $0 / 17$ & $0.45-0.95$ & 66.8 & $0 / 17$ & $0.80-0.95$ \\
\hline 7 & 42.6 & $1 / 17$ & $0.70-0.95$ & 82.5 & $1 / 17$ & $0.85-0.95$ \\
\hline 11 & 53.2 & $0 / 17$ & $0.70-0.95$ & 43.9 & $2 / 17$ & $0.75-0.95$ \\
\hline 12 & 57.8 & $17 / 17$ & $0.15-0.95$ & 26.9 & $16 / 17$ & $0.70-0.95$ \\
\hline Mean & 42.5 & $6 / 17$ & $0.35-0.95$ & 42.4 & $4 / 17$ & $0.55-0.95$ \\
\hline
\end{tabular}


For another type of RM-elements, RUL predictions by this Multi-Model-Particle Filter are realized. With regard to the adaption of the state model, the same state model with different parameters is suitable for these elements.

\subsection{Comparison of Classical One-Model Particle Filtering-based Prognostic Approach and the Developed Multi-Model-Particle Filtering-based Prognostic Approach}

To evaluate the developed Multi-Model-Particle Filtering-based prognostic approach, a comparison with the classical One-Model-Particle Filtering-based prognostic approach is given in this sub-section.

For both measurement quantities, RULs are predicted by a classical Particle Filteringbased prognostic approach. An open question regarding the application of classical Particle Filters is related to the selection of a suitable state model, especially when no physical model is available. Therefore, for the two groups, predictions for all single models are estimated. The results are analyzed by the three former performance indices. The mean performance indices over all predictions are given in Table 3. The results show that the Multi-ModelParticle Filter achieves a better performance in terms of MAPE, rate of negative errors, and prognostic horizon for most of the use case's elements. Especially for the temperature measurements, the classical One-Model-Particle Filter results in larger MAPEs. The mean MAPE of the Multi-Model-Particle Filter results on the basis of temperature measurements is $44.7 \%$ lower than the mean MAPE of the classical Particle Filter results. The results for the heat chamber group are quite similar, since the same state models are used, the additional extensions of the Multi-Model-Particle Filter and the available uncertainty lead to the differences.

Table 3. Performance indices for the displacement-based and the temperature-based predictions realized by the classical Particle Filtering-based prognostic approach.

\begin{tabular}{ccccccc}
\hline RM-Element & \multicolumn{2}{c}{ Displacement-Based Concept } & \multicolumn{2}{c}{ Temperature-Based Concept } \\
\hline & Mean MAPE & $\begin{array}{c}\text { Mean Rate of } \\
\text { Negative Errors }\end{array}$ & Mean PH & Mean MAPE & $\begin{array}{c}\text { Mean Rate of } \\
\text { Negative Errors }\end{array}$ & Mean PH \\
\hline 3 & 66.9 & $10 / 17$ & $0.40-0.95$ & 157.5 & $14 / 17$ & $0.60-0.95$ \\
\hline 4 & 44.7 & $11 / 17$ & $0.30-0.95$ & 127.4 & $14 / 17$ & $7 / 17$ \\
\hline 5 & 43.9 & $5 / 17$ & $0.45-0.95$ & 79.5 & $3 / 17$ & $0.50-0.95$ \\
\hline 6 & 49.3 & $3 / 17$ & $0.60-0.95$ & 66.3 & $0.30-0.95$ \\
\hline 7 & 79.0 & $0 / 17$ & $0.65-0.95$ & 83.3 & $0.50-0.95$ \\
\hline 11 & 43.2 & $2 / 17$ & $0.80-0.95$ & 44.7 & $0 / 17$ & $0.60-0.95$ \\
\hline 12 & 27.2 & $16 / 17$ & $0.70-0.95$ & 50.6 & $0.55-0.95$ \\
\hline Mean & 50.6 & $7 / 17$ & $0.55-0.95$ & 87.1 & $8 / 17$ & $0.15-0.95$ \\
\hline
\end{tabular}

Over all, there are individual models and thereby classical Particle Filter solutions that perform well for single elements, but worse for other elements. Moreover, during an online application, it is not known which single model is most suitable for the particular element. Therefore, the Multi-Model-Particle Filter is advantageous if multiple models of the system in focus are available. Thus, the following discussion is focused on the developed MultiModel-Particle Filter and its ability to enable a predictive maintenance strategy.

\subsection{Discussion}

As each of the three performance indices highlights one aspect of the predictions, it is desirable to take all three indices into account rather than focusing on a single index. For example, a high MAPE of element 6 and 7 comes together with small rates of negative errors and sometimes shorter prognostic horizons. In such a case, nearly all predicted RULs are too short. Based on the predictions in Table 2 the elements will be maintained prior to their end of life. Therefore, the high MAPE can be balanced by the other two indices. 
However, based on the performance evaluation of the three performance indices, it is hard to underline the advantages of the developed method for a predictive maintenance strategy. To further analyze the results and estimate the impact on a related predictive maintenance strategy, concepts for a preventive and predictive maintenance strategy based on each measurement quantity are developed and compared.

A suitable value to compare the two strategies is given by the utilization, since the used potential of the elements is described by the utilization. In industrial applications, a major aim is reducing cost. By comparing the utilization, the relevant factor of cost is considered indirectly. The utilization is estimated for both strategies by the quotient between the approximated end of life and the true end of life. The approximated end of life of each element differs for the two strategies. In the predictive strategy, it is based on the predicted RULs, in contrast to the preventive strategy where the shortest lifetime of all elements is chosen as the end of life for all elements. Therefore, the lifetime of elements 1-8 is considered for the group of stationary experiments and the lifetime of elements 11 and 12 for the group of experiments conducted in the heating chamber. To take the uncertainty into account that only a small sample is tested, further safety precautions have to be scheduled. For the calculation of the approximated end of life for the preventive strategy, the end of life is multiplied with a safety factor of 0.9 . For the predictive strategy, the uncertainty is considered by choosing the last prediction time point of $95 \%$ of reached lifetime as the time point of interest to approximate the end of life. As all predictions show, PHs beginning not later than at $85 \%$ of reached lifetime, the predictions at $95 \%$ of reached lifetime are within the acceptable range. The approximated end of life is individually selected when the predicted RUL exceeds a threshold. That threshold is defined as the minimum predicted RUL for all elements at this prediction time point. Furthermore, the maximum of these predicted RUL values is chosen.

To underline the advantages of the developed CMS, the utilization of these RMelements for a preventive and a predictive maintenance concept is estimated for both measurement quantities. In Figure 12a, the utilization of each element based on displacement measurements is given for both maintenance concepts. For the five elements tested under stationary conditions in the laboratory, the utilization of the predicted end of lifetime is up to twice as large as the utilization of the preventive strategy. Whereas, the higher level of uncertainty of the RM-elements tested in the heat chamber becomes apparent, as the preventive strategy has no advantages regarding the utilization of single elements 11 and 12.

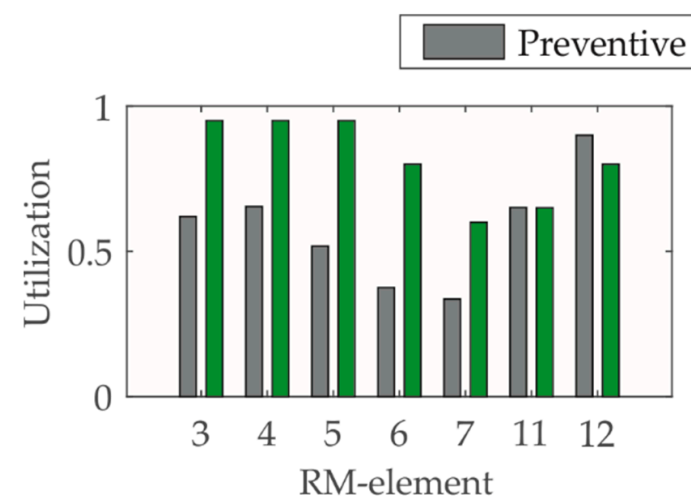

(a)

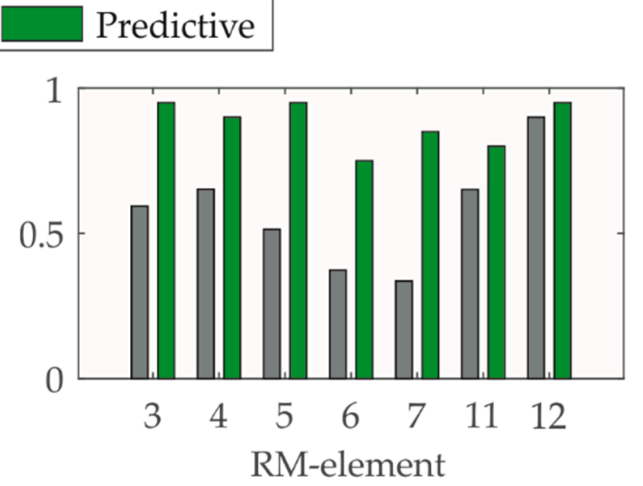

(b)

Figure 12. Comparison of two maintenance concepts for RM-elements: (a) based on displacement measurements, see Figure 8, and (b) based on temperature measurements, see Figure 7b [63].

In Figure 12b, the temperature-based results for the utilization are given. For all elements, the utilization is higher in the predictive maintenance concept. Especially, the stationary group of elements 3-7 shows a huge difference between the two concepts, e.g., by predictive maintenance the utilization of RM-element 7 could be doubled. Additionally, 
the utilization of the RM-elements 11 and 12 is up to $10 \%$ higher. Comparing both results, the displacement-based CMS achieves a 5\% higher utilization of the RM-elements 4 and 6 , while for all other elements, the utilization indicates that the temperature-based CMS is to be preferred.

\section{Conclusions}

In this paper, a method for predicting the remaining useful lifetime considering different uncertainties was developed. The developed Multi-Model-Particle Filtering-based prognostic approach allows for the utilization of multiple models in one prediction, outperforming existing approaches. Moreover, different groups of models can be implemented to differentiate between various operating or environmental conditions. As a use case, rubber-metal-elements inheriting several uncertainties are considered. Accurate predictions for the two measurement quantities, i.e., displacement amplitude and relative temperature, are realized. A comparison of the results highlights that both measurement quantities reach comparable results described by the three performance indices: mean absolute percentage error, rate of negative errors, and prognostic horizon. An additional comparison to a classical Particle Filtering-based prognostic approach based on one model has emphasized the advantages of the developed Multi-Model-Particle Filtering-based prognostic approach. Furthermore, the estimated utilization highlights the achievement of the developed approach in the context of a predictive maintenance strategy over a preventive maintenance strategy. Particularly, temperature measurements enable a higher utilization of the monitored RM-elements. Therefore, a concept for a future predictive maintenance of rubber-metal-elements is developed in this work.

The results prove that different kinds and different levels of uncertainty can be considered in condition monitoring methods. Moreover, it is recommended to take uncertainties into account at an early stage of the development of a condition monitoring system.

For the presented use case, a combination of the two chosen measurements yields the potential of further improvement. Moreover, a larger data set may decrease the uncertainty of the prognostic approach given by the standard deviation of the predicted RULs. Special performance indices could evaluate that uncertainty. Finally, the presented approach should be validated by other use cases to underline its suitability.

Funding: The content of this work was partly developed in cooperation with Jörn GmbH, Stuttgart, Germany, and was partly supported by "Bundesministerium für Wirtschaft und Energie" due to a resolution of the Deutsche Bundestag ("Zentrales Innovationsprogramm Mittelstand ZIM"), (No. ZF4032924RF8).

Conflicts of Interest: The author declare no conflict of interest.

\section{Appendix A}

Pseudo Code RUL Prediction by the Multi-Model-Particle Filter

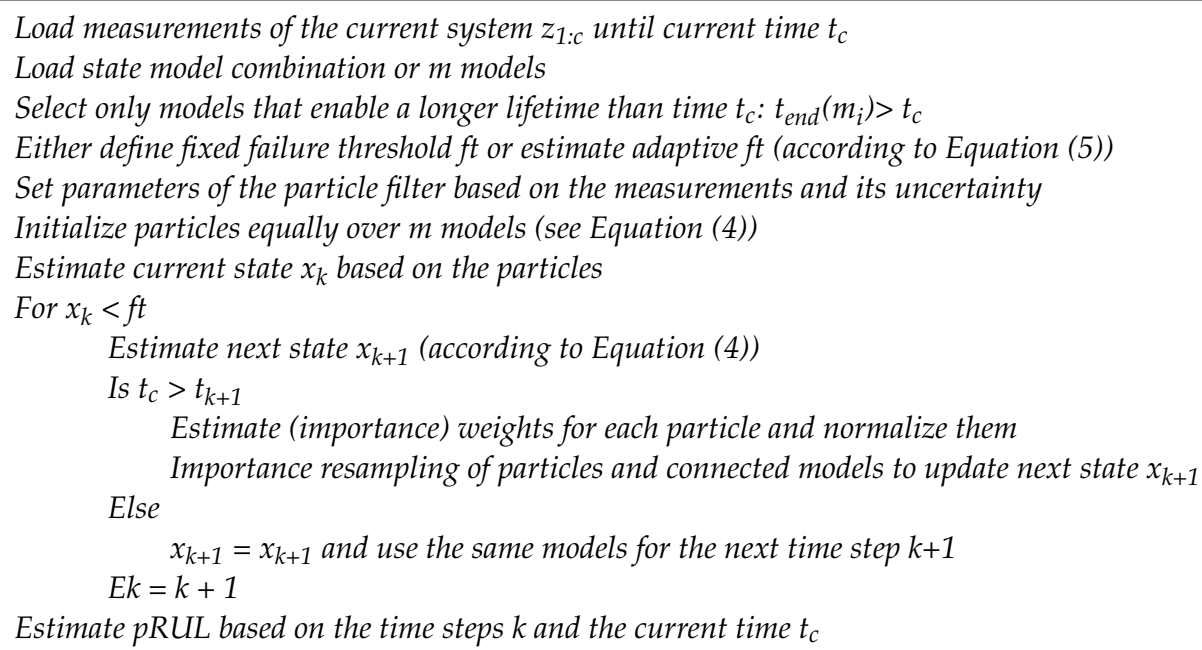




\section{References}

1. DIN ISO 17359. Zustandsüberwachung und—Diagnostik von Maschinen-Allgemeine Anleitungen; Beuth Verlag GmbH: Berlin, Germany, 2017.

2. Goebel, K.; Saxena, A.; Daigle, M.; Celaya, J.; Roychoudhury, I.; Clements, S. Introduction to Prognostics; PHM Society: Dresden, Deutschland, 2012.

3. Javed, K.; Gouriveau, R.; Zerhouni, N. State of the Art and Taxonomy of Prognostics Approaches, Trends of Prognostics Applications and open Issues towards Maturity at different Technology Readiness Levels. Mech. Syst. Signal Process. 2017, 94, 214-236. [CrossRef]

4. DIN ISO 17359. Zustandsüberwachung und—Diagnostik von Maschinen-Allgemeine Anleitungen; Beiblatt 1: Erläuterungen zu Fachbegriffen; Beuth Verlag GmbH: Berlin, Germany, 2017.

5. Chapman, P.; Clinton, J.; Kerber, R.; Khabaza, T.; Reinartz, T.; Shearer, C.; Wirth, R. CRISP-DM 1.0: Step-by-Step Data Mining Guide. 2020. Available online: https://the-modeling-agency.com/crisp-dm.pdf (accessed on 11 February 2020).

6. Touret, T.; Changenet, C.; Ville, F.; Lalmi, M.; Becquerelle, S. On the use of temperature for online condition monitoring of geared systems. Mech. Syst. Signal Process. 2018, 101, 197-210. [CrossRef]

7. Crabtree, C.J.; Zappalá, D.; Tavner, P.J. Survey of Commercially Available Condition Monitoring Systems for Wind Turbines. 2014. Available online: https:/ / dro.dur.ac.uk/12497/ (accessed on 11 February 2020).

8. Lachmann, S. Kontinuierliches Monitoring zur Schädigungsverfolgung an Tragstrukturen von Windenergieanlagen. Ph.D. Thesis, Ruhr-Universität Bochum, Bochum, Germany, 2014.

9. Lessmeier, C.; Kimotho, J.K.; Zimmer, D.; Sextro, W. Condition Monitoring of Bearing Damage in Electromechanical Drive Systems by Using Motor Current Signals of Electric Motors: A Benchmark Data Set for Data-Driven Classification. In Proceedings of the European Conference of the Prognostics and Health Management Society 2016, Bilbao, Spain, 5-8 July 2016 ; pp. 1-17.

10. Márquez, F.P.G.; Tobias, A.M.; Pérz, J.M.P.; Papaelias, M. Condition Monitoring of Wind Turbines: Techniques and methods. Renew. Energy 2012, 46, 169-178.

11. Vachtsevanos, G.J. Intelligent Fault Diagnosis and Prognosis for Engineering Systems; Wiley: Hoboken, NJ, USA, 2006.

12. Atamuradov, V.; Medjaher, K.; Dersin, P.; Lamoureux, B.; Zerhouni, N. Prognostics and Health Management for Maintenance Practitioners-Review, Implementation and Tools Evaluation. Int. J. Progn. Health Manag. 2012, 8, 1-31.

13. Baraldi, P.; di Maio, F.; Zio, E. Particle Filters for Prognostics; PHM Society: Nantes, France, 2014.

14. Chang, Y.; Fang, H.; Zhang, Y. A new hybrid Method for the Prediction of the Remaining Useful Life of a Lithium-Ion Battery, Appl. Energy 2017, 206, 1564-1578.

15. Kan, M.S.; Tan, A.C.C.; Mathew, J. A Review on Prognostic Techniques for non-stationary and non-linear Rotating Systems. Mech. Syst. Signal Process. 2015, 62-63, 1-20. [CrossRef]

16. Uckun, S.; Goebel, K.; Lucas, P.J.F. Standardizing research methods for prognostics. In Proceedings of the International Conference on Prognostics and Health Management, 2008: PHM 2008, Denver, CO, USA, 6-9 October 2008; pp. 1-10.

17. Jouin, M.; Gouriveau, R.; Hissel, D.; Péra, M.-C.; Zerhouni, N. Particle Filter-Based Prognostics: Review, Discussion and Perspectives. Mech. Syst. Signal Process. 2016, 72-73, 2-31. [CrossRef]

18. An, D.; Kim, N.H.; Choi, J.-H. Options for prognostics methods: A review of data-driven and physics-based prognostics. In Proceedings of the Annual Conference of the PHM Society, New Orleans, LA, USA, 14-17 October 2013; pp. 1-14.

19. Guo, L.; Peng, Y.; Liu, D.; Luo, Y. Comparison of resampling algorithms for particle filter based remaining useful life estimation. In Proceedings of the 2015 IEEE Conference on Prognostics and Health Management (PHM), Coronado, CA, USA, 18-24 October 2015; pp. 1-8.

20. Doucet, A.; Godsill, S.; Andrieu, C. On sequential Monte Carlo sampling methods for Bayesian filtering. Stat. Comput. 2000, 10, 197-208. [CrossRef]

21. Kimotho, J.K. Development and Performance Evaluation of Prognostic Approaches for Technical Systems; Universitat Paderborn: Paderborn, Germany, 2016.

22. Wang, J.; Gao, R.X. Multiple model particle filtering for bearing life prognosis. In Proceedings of the 2013 IEEE Conference on Prognostics and Health Management, Gaithersburg, MD, USA, 24-27 June 2013.

23. Saha, B.; Goebel, K. Modeling li-ion battery capacity depletion in a particle filtering framework. In Proceedings of the Annual Conference of the PHM Society 2009, San Diego, CA, USA, 27 September-1 October 2009; pp. 1-10.

24. Alonso, J.A.O.; Weihrauch, C.; Bertram, T. A Model-Based Approach for Predicting the Remaining Driving Range in Electric Vehicles. In Proceedings of the Annual Conference of the Prognostics and Health Management Society, New Orleans, LA, USA, 14-17 October 2013.

25. Caesarendra, W.; Niu, G.; Yang, B.-S. Machine condition prognosis based on sequential Monte Carlo method. Expert Syst. Appl. 2010, 37, 2412-2420. [CrossRef]

26. Kimotho, J.K.; Meyer, T.; Sextro, W. PEM fuel cell prognostics using particle filter with model parameter adaptation. In Proceedings of the 2014 IEEE Conference on Prognostics and Health Management, Cheney, WA, USA, 22-25 June 2014.

27. Jouin, M.; Gouriveau, R.; Hissel, D.; Péra, M.-C.; Zerhouni, N. Prognostics of PEM Fuel Cells under a combined Heat and Power Profile. IFAC-PapersOnLine 2015, 48, 26-31. [CrossRef]

28. Arachchige, B.; Perinpanayagam, S.; Jaras, R. Enhanced Prognostic Model for Lithium Ion Batteries Based on Particle Filter State Transition Model Modification. Appl. Sci. 2017, 7, 1172. [CrossRef] 
29. Laayouj, N.; Jamouli, H. Prognosis of Degradation based on a new dynamic Method for Remaining Useful Life Prediction. J. Qual. Maint. Eng. 2017, 23, 239-255. [CrossRef]

30. Jimenez, J.J.M.; Schwartz, S.; Vingerhoeds, R.; Grabot, B.; Salaün, M. Towards multi-model approaches to predictive maintenance: A systematic literature survey on diagnostics and prognostics. J. Manuf. Syst. 2020, 56, 539-557. [CrossRef]

31. Li, P.; Kadirkamanathan, V. Particle filtering based multiple-model approach to fault diagnosis in nonlinear stochastic systems. In Proceedings of the 2001 European Control Conference (ECC), Porto, Portugal, 4-7 September 2001; pp. 1378-1383.

32. Cadini, F.; Sbarufatti, C.; Corbetta, M.; Giglio, M. A particle filter-based model selection algorithm for fatigue damage identification on aeronautical structures. Struct. Control Health Monit. 2017, 24, e2002. [CrossRef]

33. Zhang, Z.; Chen, J. Fault detection and diagnosis based on particle filters combined with interactive multiple-model estimation in dynamic process systems. ISA Trans. 2019, 85, 247-261. [CrossRef]

34. Akca, A.; Efe, M.Ö. Multiple Model Kalman and Particle Filters and Applications: A Survey. IFAC-PapersOnLine 2019, 52, 73-78. [CrossRef]

35. Kimotho, J.K.; Sondermann-Woelke, C.; Meyer, T.; Sextro, W. Machinery Prognostic Method Based on Multi-Class Support Vector Machines and Hybrid Differential Evolution-Particle Swarm Optimization. Chem. Eng. Trans. 2013, 33, 619-624. [CrossRef]

36. Chehade, A.; Bonk, S.; Liu, K. Sensory-Based Failure Threshold Estimation for Remaining Useful Life Prediction. IEEE Trans. Reliab. 2017, 66, 939-949. [CrossRef]

37. Goebel, K.; Daigle, M.; Saxena, A.; Sankararaman, S.; Roychoudhury, I.; Celaya, J. Prognostics: The Science of Prediction, 1st ed.; CreateSpace Independent Publishing Platform: Scotts Valley, CA, USA, 2017.

38. Koenen, J.F. Ein Beitrag zur Beherrschung von Unsicherheit in Lastmonitoring-Systemen. Ph.D. Thesis, Universität Siegen, Siegen, Germany, 2016.

39. Baraldi, P.; Popescu, I.C.; Zio, E. Methods of Uncertainty Analysis in Prognostics. 2012. Available online: https:/ /hal-supelec. archives-ouvertes.fr/hal-00609156 (accessed on 11 February 2020).

40. Valeti, B.; Pakzad, S.N. Remaining useful life estimation of wind turbine blades under variable wind speed conditions using particle filters. In Proceedings of the Annual Conference of the PHM Society 2018, Philadelphia, PA, USA, 24-27 September 2018; pp. 1-10.

41. Baraldi, P.; Mangili, F.; Zio, E. Investigation of uncertainty treatment capability of model-based and data-driven prognostic methods using simulated data. Reliab. Eng. Syst. Saf. 2013, 112, 94-108. [CrossRef]

42. Su, X.; Wang, S.; Pecht, M.; Zhao, L.; Ye, Z. Interacting Multiple Model Particle Filter for Prognostics of Lithium-Ion Batteries. Microelectron. Reliab. 2017, 70, 59-69. [CrossRef]

43. Sankararaman, S.; Goebel, K. Uncertainty in Prognostics and Systems Health Management, Int. J. Progn. Health Manag. 2015, 6, $1-14$.

44. Usynin, A.; Hines, J.W.; Urmanov, A. Uncertain failure thresholds in cumulative damage models. In Proceedings of the Annual Reliability and Maintainability Symposium, 2008: RAMS 2008, Las Vegas, NV, USA, 28-31 January 2008; pp. 334-340.

45. Acuña-Ureta, D.E.; Orchard, M.E.; Wheeler, P. Computation of time probability distributions for the occurrence of uncertain future events. Mech. Syst. Signal Process. 2021, 150, 107332. [CrossRef]

46. Peng, W.; Ye, Z.-S.; Chen, N. Bayesian Deep-Learning-Based Health Prognostics Toward Prognostics Uncertainty. IEEE Trans. Ind. Electron. 2020, 67, 2283-2293. [CrossRef]

47. Kraemer, P. Schadensdiagnoseverfahren für die Zustandsüberwachung von Offshore-Windenergieanlagen. Ph.D. Thesis, Universität Siegen, Siegen, Germany, 2011.

48. Sharma, A.; Golubchik, L.; Govindan, R. On the Prevalence of Sensor Faults in Real-World Deployments. In Proceedings of the 4th Annual IEEE Communications Society Conference on Sensor, Mesh and Ad Hoc Communications and Networks, San Diego, CA, USA, 18-21 June 2007; pp. 213-222.

49. Chen, J.; Ma, C.; Song, D.; Xu, B. Failure Prognosis of multiple uncertainty system based on Kalman filter and its application to aircraft fuel system. Adv. Mech. Eng. 2016, 8, 1-13. [CrossRef]

50. Corbetta, M.; Sbarufatti, C.; Saxena, A.; Goebel, K. A Bayesian framework for fatigue life prediction of composite laminates under co-existing matrix cracks and delamination. Compos. Struct. 2018, 187, 58-70. [CrossRef]

51. Tamssaouet, F.; Nguyen, K.T.P.; Medjaher, K.; Orchard, M. A contribution to online system-level prognostics based on adaptive degradation models. In Proceedings of the Fifth European Conference of the PHM Society 2020, virtual, $27-31$ July 2020.

52. Li, Z.; Goebel, K.; Wu, D. Degradation Modeling and Remaining Useful Life Prediction of Aircraft Engines Using Ensemble Learning. J. Eng. Gas Turbines Power 2019, 141, 1-10. [CrossRef]

53. Nielsen, J.S.; Sorensen, J.D. Bayesian Estimation of Remaining Useful Life for Wind Turbine Blades. Energy 2017, $10,664$. [CrossRef]

54. Wen, Y.; Wu, J.; Yuan, Y. Multiple-Phase Modeling of Degradation Signal for Condition Monitoring and Remaining Useful Life Prediction. IEEE Trans. Reliab. 2017, 66, 924-938. [CrossRef]

55. Orchard, M.; Kacprzynski, G.; Goebel, K.; Saha, B.; Vachtsevanos, G. Advances in uncertainty representation and management for particle filtering applied to prognostics. In Proceedings of the 2008 International Conference on Prognostics and Health Management, Denver, CO, USA, 6-9 October 2008; pp. 1-6.

56. Sankararaman, S. Significance, Interpretation, and Quantification of Uncertainty in Prognostics and Remaining Useful Life Prediction. Mech. Syst. Signal Process. 2015, 52-53, 228-247. [CrossRef] 
57. Arulampalam, M.S.; Maskell, S.; Gordon, N.; Clapp, T. A Tutorial on Particle Filters for Online Nonlinear/Non-Gaussian Bayesian Tracking. IEEE Trans. Signal Process. 2002, 50, 174-188. [CrossRef]

58. Müller-Gronbach, T.; Novak, E.; Ritter, K. Monte Carlo-Algorithmen; Springer: Berlin/Heidelberg, Germany, 2012.

59. Papoulis, A.; Pillai, S.U. Probability, Random Variables, and Stochastic Processes, 4th ed.; McGraw-Hill: Boston, MA, USA, 2002.

60. Seifzadeh, S.; Khaleghi, B.; Karay, F. Soft-data-constrained multi-model particle filter for agile target tracking. In Proceedings of the 16th International Conference on Information Fusion (FUSION), Istanbul, Turkey, 9-12 July 2013; pp. 564-571.

61. Junyu, Q.; Gryllias, K.; Mauricio, A. Multiple-Model Estimation-based Prognostics for Rotating Machinery. In Proceedings of the European Conference of Prognostics and Health Management 2021, (virtual), Turin, Italy, 28 June-2 July 2021.

62. de Micheaux, H.L.; Ducottet, C.; Frey, P. Online multi-model particle-filter-based tracking to study bedload transport. In Proceedings of the IEEE International Conference on Image Processing (ICIP 2016), Phoenix, AZ, USA, 25-28 September 2016; pp. 3489-3493.

63. Bender, A. Zustandsüberwachung zur Prognose der Restlebensdauer von Gummi-Metall-Elementen unter Berücksichtigung systembasierter Unsicherheiten. Ph.D. Thesis, Universität Paderborn, Paderborn, Germany, 2021.

64. Nystad, B.H.; Gola, G.; Hulsund, J.E. Lifetime models for remaining useful life estimation with randomly distributed failure thresholds. In Proceedings of the European Conference of Prognostics 2012, Dresden, Germany, 3-5 July 2012.

65. Orchard, M.E.; Vachtsevanos, G.J. A Particle-Filtering Approach for on-line Fault Diagnosis and Failure Prognosis. Trans. Inst. Meas. Control 2009, 31, 221-246. [CrossRef]

66. Jablonski, A.; Barszcz, T.; Bielecka, M.; Breuhaus, P. Modeling of Probability Distribution Functions for automatic Threshold Calculation in Condition Monitoring Systems. Measurement 2013, 46, 727-738. [CrossRef]

67. Bender, A.; Schinke, L.; Sextro, W. Remaining useful lifetime prediction based on adaptive failure thresholds. In Proceedings of the 29th European Safety and Reliability Conference, Hannover, Germany, 22-26 September 2019; pp. 1262-1269.

68. Domininghaus, H.; Elsner, P.; Eyerer, P.; Hirth, T. (Eds.) Kunststoffe: Eigenschaften und Anwendungen, 8th ed.; Springer: Berlin/Heidelberg, Germany, 2012.

69. Baur, E.; Brinkmann, S.; Osswald, T.A.; Schmachtenberg, E. Saechtling Kunststoff Taschenbuch, 30th ed.; Carl Hanser Verlag: München, Germany, 2007.

70. Johlitz, M. Zum Alterungsverhalten von Polymeren: Experimentell gestützte, Thermo-Chemomechanische Modellbildung und Numerische Simulation. Habilitation, Universität der Bundeswehr München, München, Germany, 2015.

71. Molls, M. Experimentelle und Numerische Untersuchung Ein- und Mehrachsig Belasteter Elastomerbuchsen unter Besonderer Berücksichtigung des Reihenfolgeneinflusses. Ph.D. Thesis, Universität Duisburg-Essen, Duisburg-Essen, Germany, 2013.

72. Mistler, M. Lebensdauerprognose für dynamisch beanspruchte Elastomerbauteile auf Basis der thermo-mechanischen Materialbeanspruchung. Ph.D. Thesis, Universität Duisburg-Essen, Duisburg-Essen, Germany, 2018.

73. Flamm, M.; Steinweger, T.; Weltin, U. Festigkeitshypothesen in der rechnerischen Lebensdauervorhersage von Elastomeren. KGK Kautschuk Gummi Kunststoffe 2003, 56, 582-586.

74. DIN 50100. Schwingfestigkeitsversuch-Durchführung und Auswertung von zyklischen Versuchen mit konstanter Amplitude für metallishe Werkstoffproben und Bauteile; Beuth Verlag GmbH: Berlin, Germany, 2016.

75. Flamm, M.; Steinweger, T.; Weltin, U. Lebensdauerabschätzung auf Basis eines lokalen Konzepts. In Elastomerbauteile: DVM-Tag 2009; Berlin, Germany, 2009; pp. 79-88.

76. Giese, U. Aufklärung Ermüdungs- und Schädigungsrelevanter Mechanismen bei Dynamisch Belasteten Technischen Gummiwerkstoffen. Schlussbericht des IGF-Vorhabens Nr. 15694N. 2011. Available online: https://www.dikautschuk.de/fileadmin/files/ forschung/abschlussbericht_aif_15694n.pdf (accessed on 3 August 2020).

77. Bender, A.; Kaul, T.; Sextro, W. Entwicklung eines Condition Monitoring Systems für Gummi-Metall-Elemente. In Wissenschaftsund Industrieforum 2017: Intelligente Technische Systeme, Paderborn; Paderborn, Germany, 2017; pp. 347-358.

78. Spitz, M. Modellbasierte Lebensdauerprognose für dynamisch beanspruchte Elastomerbauteile. Ph.D. Thesis, Universität Duisburg-Essen, Duisburg Essen, Germany, 2012.

79. Abraham, F.; Alshuth, T.; Jerrams, S. Ermüdungsbeständigkeit von Elastomeren in Abhängigkeit von der Spannungsamplitude und der Unterspannung. Available online: https:/ / www.dikautschuk.de/fileadmin/files/leseproben/p_0135.pdf (accessed on 6 April 2018).

80. Das, S.N.; Chaudhuri, A.R. Estimation of Life of an Elastomeric Component: A Stochastic Model. DSJ 2011, 61, 257-263. [CrossRef]

81. Ludwig, M. Entwicklung eines Lebensdauer-Vorhersagekonzepts für Elastomerwerkstoffe unter Berücksichtigung der Fehlstellenstatistik. Ph.D. Thesis, Gottfried Wilhelm-Leibniz-Universität Hannover, Hannover, Germany, 2017.

82. Zarrin-Ghalami, T. Fatigue Life Prediction and Modeling of Elatomeric Components. Ph.D. Thesis, The University of Toledo, Toledo, OH, USA, 2013.

83. Harbour, R.J.; Fatemi, A.; Mars, W.V. Fatigue Crack Growth of filled Rubber under constant and variable Amplitude Loading Condition. Fat Frac. Eng. Mat. Struct. 2007, 30, 640-652. [CrossRef]

84. Kroth, T.; Möller, R.; Melz, T.; Dippel, B.; Lion, A. Konzept zur temperaturabhängigen Lebensdauerabschätzung von Elastomerbauteilen. KGK Kautschuk Gummi Kunststoffe 2016, 4, 44-51.

85. Meyer, R. Konzept zur Lebensdauerabschätzung von Elastomerbauteilen mit Hilfe der FEM und Fuzzy-Logik. In Proceedings of the Elastomerbauteile: DVM-Tag 2009, Berlin, Germany, 22-24 April 2009; pp. 103-112. 
86. Steinweger, T. Lebensdauerberechnung und Lebensdauerprüfung von Elastomerbauteilen unter mehrachsiger dynamischer Belastung. Schlussbericht. 2006. Available online: http://www.cleaner-production.de/fileadmin/assets/bilder/BMBF-Projekte/ 01RC0137_-_Abschlussbericht.pdf (accessed on 3 August 2020).

87. Flamm, M.; Steinweger, T.; Weltin, U. Schadensakkumulation bei Elastomeren. KGK Kautschuk Gummi Kunststoffe 2002, 55, 665-668.

88. Wortberg, J.; Mistler, M.; Schulze, A. Lifetime Prediction with nonlinear Damage Accumulation based on Material Stressing Part II: Application to Elastomer Couplings. KGK Kautschuk Gummi Kunststoffe 2017, 8, 55-60.

89. Platt, W. Betriebssicherheit von elastomerbestückten Wellenkupplungen unter besonderer Berücksichtigung der Einsatztemperatur. Ph.D. Thesis, Rheinisch-Westfälische Technische Hochschule Aachen, Aachen, Germany, 1988.

90. Ziegler, C.; Mehling, V.; Baaser, H.; Häusler, O. Ermüdung und Risswachstum bei Elastomerbauteilen. In Proceedings of the Elastomerbauteile: DVM-Tag 2009, Berlin, Germany, 22-24 April 2009; pp. 121-130.

91. Bender, A.; Sextro, W.; Reinke, K. Neuartiges Konzept zur Lebensdauerprognose von Gummi-Metall-Elementen. In Proceedings of the VDI-Fachtagung Schwingungen von Windenergieanlagen 2017, Bremen, Germany, 10 October 2017; pp. 49-60.

92. Hoenig, M.; Hagmeyer, S.; Zeiler, P. Enhancing Remaining Useful Lifetime Prediction by an Advanced Ensemble Method Adapted to the Specific Characteristics of Prognostics and Health Management. In Proceedings of the 29th European Safety and Reliability Conference, Hannover, Germany, 22-26 September 2019; pp. 1155-1162.

93. Abid, K.; Sayed-Mouchaweh, M.; Cornez, L. Adaptive machine learning approach for fault prognostics based on normal conditions: Application to shaft bearings of wind turbine. In Proceedings of the Annual Conference of the PHM Society 2019, Scottsdale, AZ, USA, 23-26 September 2019. 